\title{
Orbital metastasis secondary to pulmonary adenocarcinoma treated with gefitinib: a case report
}

\author{
Yasuko Koma1", Keiko Goto', Chihiro Yoshida', Kengo Kimura', Yusuke Matsumoto', Midori Koyama', \\ Nariyasu Nakashima', Daiki Masuya', Hirofumi Matsuoka', Harukazu Yoshimatsu', Atsushi Azumi² \\ and Yujiro Suzuki
}

\begin{abstract}
Introduction: Orbital metastases of lung cancer are rare. However, because the number of patients diagnosed with lung cancer is increasing, the probability that a physician will see a patient with an orbital metastasis is also increasing. Unfortunately, the clinical course and response of these patients to cytotoxic chemotherapy are generally poor and keeping a patient's quality of vision is difficult. In recent years, gefitinib, an epidermal growth factor receptor tyrosine kinase inhibitor, has brightened the outlook for patients with advanced non-small cell lung cancer, especially for those who carry epidermal growth factor receptor-activating mutations.
\end{abstract}

Case presentation: A 62-year-old Japanese man presented with swelling of the eyelid margin and ptosis of his right eye. A physical examination revealed double vision in his right eye and an alteration in elevator muscle mobility. A magnetic resonance image demonstrated a right intra-orbital mass $(18 \times 16 \mathrm{~mm})$. Screening examinations were carried out because this mass was suspected to be a metastasis from another organ. Chest computed tomography revealed a $42 \times 37 \mathrm{~mm}$ mass shadow on the left side of the hilum with mediastinal lymph node metastases. Adenocarcinoma with an epidermal growth factor receptor gene mutation (exon 19 deletion L747-E749; A750P) was detected in a transbronchial biopsy specimen; the patient was diagnosed with stage IV (T2N2M1) non-small cell lung cancer.

Gefitinib (250mg/day) was chosen as first-line chemotherapy because there was no pre-existing interstitial shadow. After two months of treatment, the patient's right eye opened completely and follow-up magnetic resonance imaging revealed a marked reduction of the intra-orbital mass to $14 \times 13 \mathrm{~mm}$. Three months after treatment initiation, a follow-up computed tomography showed a marked reduction in the size of the primary lesion to $23 \times$ $20 \mathrm{~mm}$. The patient is continuing gefitinib treatment without any adverse effects noted on computed tomography, physical, or laboratory examination.

Conclusions: We report the case of a patient with an orbital non-small cell lung cancer metastasis with epidermal growth factor receptor-activating mutations. This metastasis, as well as the primary lesion, showed a marked response to the molecular targeting drug gefitinib, and the patient's vision was kept without an invasive procedure. Gefitinib may be a good first choice for patients with orbital non-small cell lung cancer metastasis harboring epidermal growth factor receptor-activating mutations.

\section{Introduction}

Orbital metastases of cancer are rare, accounting for $7 \%$ of intra-orbital tumors [1]. They most commonly originate

\footnotetext{
* Correspondence: yasukok@shinkohp.or.jp

${ }^{1}$ Respiratory Center, Shinko Hospital, 1-4-47, Wakinohamacho, Chuo-ku, Kobe 651-0072, Japan

Full list of author information is available at the end of the article
}

from primary lesions of the breast (48\%), prostate and skin (melanoma) (12\%), lung (8\%), and kidney (7\%) [1]. The clinical course of patients with orbital metastases of lung cancer depends on the nature of the primary tumor, such as its histological types; the prognosis is poor in most cases with an average survival of 7.4 months [2].

\section{Biomed Central}

(c) 2012 Koma et al.; licensee BioMed Central Ltd. This is an Open Access article distributed under the terms of the Creative Commons Attribution License (http://creativecommons.org/licenses/by/2.0), which permits unrestricted use, distribution, and reproduction in any medium, provided the original work is properly cited. 

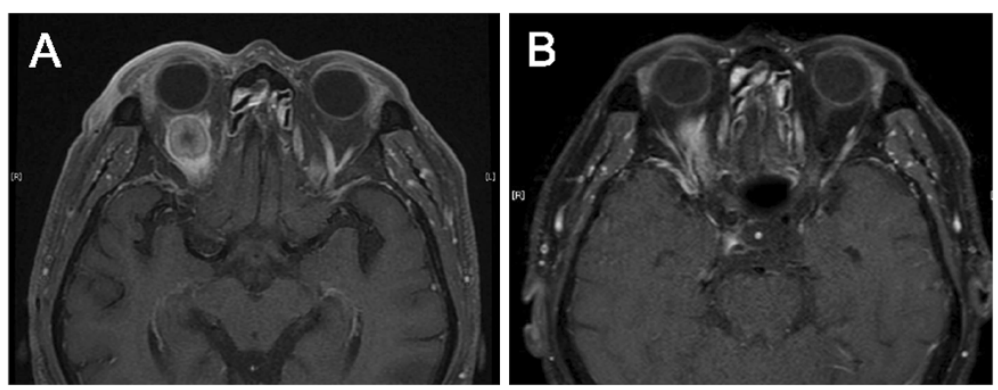

Figure 1 Brain magnetic resonance image. A: Showing an intra-orbital mass on the right side before gefitinib therapy. B: Revealing a reduction of the intra-orbital mass after two months of gefitinib therapy.

However, recent studies have revealed the favorable efficacy of gefitinib, an epidermal growth factor receptor (EGFR) tyrosine kinase inhibitor, compared with that of combination cytotoxic chemotherapy in patients with EGFR-activating mutations [3]. To the best of our knowledge, no report has published the effect of gefitinib on an orbital metastasis.

Here we present the case of a patient with orbital metastasis of lung adenocarcinoma which showed a good response to gefitinib therapy in both the primary lesion and orbital metastasis improving the patient's quality of vision.

\section{Case presentation}

A 62-year-old Japanese man presented with swelling of the eyelid margin and ptosis of his right eye. He was a heavy cigarette smoker (30 cigarettes per day for 50 years). He had no other significant medical history. A physical examination revealed double vision in the right eye and an alteration in elevator muscle mobility. The patient's visual acuity was not reduced; there was no increased intra-ocular pressure.

A magnetic resonance image (MRI) demonstrated a right intra-orbital mass $(18 \times 16 \mathrm{~mm}$; Figure $1 \mathrm{~A})$ with bone destruction at the left temporal bone (figure not shown). Screening examinations were carried out because this mass was suspected to be a metastasis from another organ. Chest computed tomography (CT) revealed a $42 \times$
$37 \mathrm{~mm}$ mass shadow on the left side of the hilum with mediastinal lymph node metastases (Figure 2A). Adenocarcinoma with an EGFR gene mutation (exon 19 deletion L747E749; A750P) was detected in a transbronchial biopsy specimen; the patient was diagnosed with stage IV (cT2N2M1b) non-small cell lung cancer (NSCLC). The tumor marker carcinoembryonic antigen (CEA) was elevated to $71.2 \mathrm{ng} / \mathrm{mL}$ (normal range $<5 \mathrm{ng} / \mathrm{mL}$ ).

Gefitinib $(250 \mathrm{mg} /$ day) was chosen as the first-line chemotherapy because there was no pre-existing interstitial shadow. The patient's ptosis slightly improved after two weeks of therapy; after two months of treatment his right eye opened completely and exhibited improved mobility. Follow-up MRI revealed a marked reduction of the intra-orbital mass to $14 \times 13 \mathrm{~mm}$ (Figure 1B). Three months after treatment initiation, a follow-up CT showed a marked reduction in the size of the primary lesion to $23 \times 20 \mathrm{~mm}$ (Figure 2B). In addition, CEA decreased to $5.5 \mathrm{ng} / \mathrm{mL}$. The patient is continuing gefitinib treatment without any adverse effects noted on CT, physical, or laboratory examination.

\section{Discussion}

Orbital metastases have been reported to originate in many organs. No matter from where the primary lesion originates, orbital metastases generally lead to an alteration in ocular motility, and proptosis due to an increase in intra-orbital volume that reduces vision [4]. Of cases

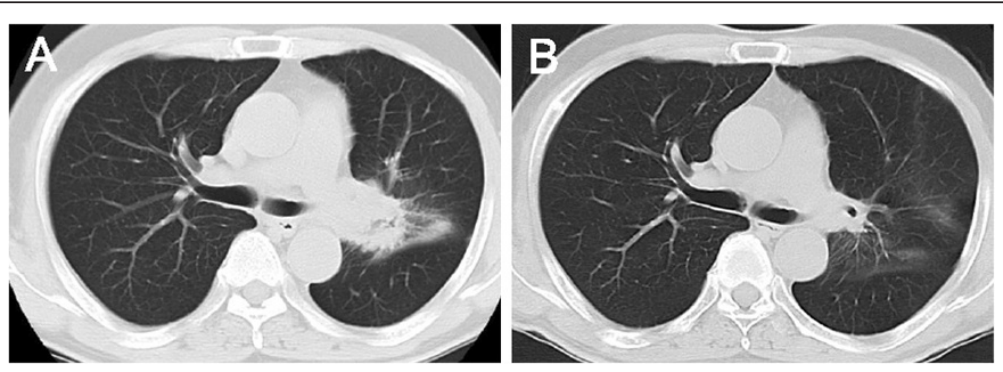

Figure $\mathbf{2}$ Chest computed tomography images. A: Showing a mass shadow on the left side of the hilum before gefitinib therapy. B: Revealing a good response of the primary tumor after three months of gefitinib therapy. 
with orbital metastases and tumor invasion of the optic nerve, $20 \%$ showed a reduction in vision [5].

Because treating an orbital metastasis is not a complete cure, therapy targeting the primary lung cancer must take precedence. Sometimes an invasive procedure, radiotherapy and orbital surgery may be undertaken to relieve the patient's pain or because the patient's vision is important to their quality of life [1].

The number of patients diagnosed with lung cancer is increasing and because the lung is one of the most frequent reported origins of orbital metastases, the probability that a physician will see a patient with an orbital metastasis is also increasing. The most frequent pathological types are adenocarcinoma (65\%) and more than half of them are of the poorly differentiated type [2]. The EGFR mutation rate of cases with orbital metastases is unknown.

The choice of a systemic therapy agent for stage IV lung cancer with metastases depends on the histological type of the primary tumor. In small cell lung cancer (SCLC), cytotoxic chemotherapy (usually a platinumbased combination therapy) is effective for orbital metastases as well as for the primary lesion. Unfortunately, cytotoxic chemotherapy does not show as quick a response for NSCLC as it does for SCLC. Recently, several novel antitumor agents have brightened the outlook for patients with advanced NSCLC; in fact, Zarogoulidis et al. reported favorable efficacy of combination chemotherapy including bevacizumab and pemetrexed in patients with orbital metastasis [6]. Gefitinib shows a rapid and improved response rate over combination chemotherapy in patients with NSCLC harboring EGFRactivating mutations [3]. The efficacy of gefitinib could be expected to apply not only to the primary lesion, but also to metastatic lesions. This case showed the efficacy of gefitinib to orbital metastasis with high response rate. Thus, the patient's quality of vision could be saved without an invasive procedure. Unfortunately, however, patients usually acquire resistance to gefitinib around 12 months of treatment [3]. Further studies will be needed to elucidate the efficacy of gefitinib on metastasis.

\section{Conclusion}

Here we present the case of a patient with orbital metastasis of lung adenocarcinoma in which a marked positive response to gefitinib therapy was shown in both the primary lesion and orbital metastasis. Gefitinib therapy improved the patient's quality of vision without an invasive procedure. Patients with orbital metastases are in need of highly effective treatment if their vision is to be spared; gefitinib may be a good first choice for patients with NSCLC and EGFR-activating mutations.

\section{Consent}

Written informed consent was obtained from the patient for publication of this case report and accompanying images. A copy of the written consent is available for review by the Editor-in-Chief of this journal.

Competing interests
The authors declare that they have no competing interests.

\section{Authors' contributions}

YK analyzed and interpreted the patient data, and was a major contributor in writing the manuscript. KG analyzed and interpreted the patient data regarding pulmonary oncology. $\mathrm{CY}, \mathrm{KK}, \mathrm{YM}, \mathrm{MK}, \mathrm{NN}, \mathrm{DM}, \mathrm{HM}$ and $\mathrm{HY}$ performed the bronchoscopic examination. AA performed the physical examination of the eye and interpreted the patient data regarding ophthalmological disease. YS supervised the concept and design of the manuscript. All authors read and approved the final manuscript.

\section{Author details}

'Respiratory Center, Shinko Hospital, 1-4-47, Wakinohamacho, Chuo-ku, Kobe 651-0072, Japan. ${ }^{2}$ Department of Ophthalmology, Kobe Kaisei Hospital, 3-11-15, Shinoharakitamachi, Nada-ku, Kobe 657-0068, Japan.

Received: 18 July 2012 Accepted: 13 September 2012

Published: 18 October 2012

\section{References}

1. Shields JA, Shields CL, Scartozzi R: Survey of 1264 patients with orbital tumors and simulating lesions: the 2002 Montgomery Lecture, part 1. Ophthalmology 2004, 111:997-1008.

2. Mori H, Maekawa N, Satoda N, et al: A case of primary lung cancer with initial symptoms due to orbital metastases. Nihon Kokyuki Gakkai Zasshi 2003, 41:19-24.

3. Mitsudomi T, Morita S, Yatabe Y, et al: Gefitinib versus cisplatin plus docetaxel in patients with non-small-cell lung cancer harbouring mutations of the epidermal growth factor receptor (WJTOG3405): an open label, randomised phase 3 trial. Lancet Oncol 2010, 11:121-128.

4. González F, López-Couto C: Orbital metastases. A report of four cases and a review of the literature. Arch Soc Esp Oftalmol 2006, 81:451-462.

5. Goldberg RA, Rootman J, Cline RA: Tumors metastatic to the orbit: a changing picture. Surv Ophthalmol 1990, 35:1-24. Review.

6. Zarogoulidis $P$, Terzi $E$, Kouliatsis $G$, et al: Orbital metastases as the first manifestation of lung adenocarcinoma. Case Report Ophthalmol 2011, 2:34-38.

\section{doi:10.1186/1752-1947-6-353}

Cite this article as: Koma et al:: Orbital metastasis secondary to pulmonary adenocarcinoma treated with gefitinib: a case report. Journal of Medical Case Reports 2012 6:353.

\section{Submit your next manuscript to BioMed Central and take full advantage of:}

- Convenient online submission

- Thorough peer review

- No space constraints or color figure charges

- Immediate publication on acceptance

- Inclusion in PubMed, CAS, Scopus and Google Scholar

- Research which is freely available for redistribution 